\title{
QUALITY OF LIFE IN THE CAREGIVERS OF SCHIZOPHRENIC PATIENTS
}

\author{
Mondal Anwesha, Ali Mir Shahid, Mahto J, Prakash Jai
}

\begin{abstract}
Background: Caregivers play an important role in the support, management, recovery and care of schizophrenia patients throughout life. Caregivers not only manage the patient in home situation but also help in improving the condition and prevent from further relapse. While supporting the patients emotionally, financially and socially it often results in feelings of burden in caregivers. This affects the caregiver's overall life and specifically their quality of life adversely. Objective: The present study is an attempt to explore the quality of life in the caregivers of inpatient and outpatient schizophrenia patients. Method: A total of 40 schizophrenia patients, 20 inpateint and 20 outpatient, along with their caregivers were selected by using purposive sampling technique from PGIBAMS, Raipur (C.G). Brief Psychiatric Rating Scale (BPRS) was administered on the patient to assess the severity of the symptoms and WHO-Quality of Life-Bref was administered on the caregivers to assess the quality of life. Results: Caregivers of inpatient schizophrenia patient showed disturbances in social functioning in terms of impaired interpersonal relationships and poor social support than caregivers of outpatient schizophrenic patients. Severity of symptoms has been found to be negatively correlated with physical health area of the caregivers indicating lack of energy, fatigability, impaired work performance, disturbed sleep and inability to get relaxed. Conclusion: The study highlights that the caregivers of inpatient schizophrenic patients face problems in the social functioning area, personal relationships and support system in comparison to the caregivers of outpatient schizophrenic patients. Caregivers also exhibited problems in their physical health as the severity of symptoms in schizophrenic patients increase.
\end{abstract}

Key words : - care-givers, quality of life, schizophrenia

\section{INTRODUCTION}

Quality of life refers to the satisfaction of an individual's values, goals and needs through the actualisation of their abilities or lifestyle" (Emerson, 1985). Quality of life is a broad concept that incorporates different aspects of life such as social recognition, social satisfaction, security, physical well being, philosophy of life. (Oort, et al., 2005). It is affected in a complex way by the person's physical health, psychological state, personal beliefs, social relationships and their relationship to salient features of their environment"(Oort, 2005). The WHO de? nes Quality of Life as 'an individual's perception of their position in life in the context of the culture and value systems in which they live, and in relation to their goals, expectations, standards and concerns'. Quality of life is considered to be a result of physical, mental, social and spiritual well-being (Ferrell, 1995).
Caregivers' quality of life get affected adversely while caring the patients suffering from schizophrenia because it is a disabling and severe psychiatric disorder. It effects the patients suffering with it as well as the functioning and psychosocial well being of caregivers. Main caregiver is the person belonging to the patient's informal support system who takes the responsibility of the patient and who commits most of his or her time to that task without receiving any economic retribution (Dwyer, et al., 1994). A caregiver helps a patient with his or her activities of daily living. This responsibility often creates a burden and effects the quality of life of the caregiver viz. social, personal, economic etc.

A vast amount of studies have proposed that there is a significant decrease in the quality of life of the caregivers of schizophrenia patients. Burden on relatives/caregivers has been found associated with an important reduction in their quality of life, causing damage in caregiver's health condition (Fadden, et 
al., 1987). Poor quality of life of caregivers of individuals with schizophrenia has also been observed by Boyer, et al., (2012).

Research on caregivers' quality of life is thus of importance both for the caregivers themselves and indirectly for patients' health. The aim of this present study is to assess the difference in quality of life of the caregivers of inpatient and outpatient schizophrenia patients.

\section{METHODOLGY}

\section{Sample}

For the purpose of study 40 patients diagnosed as schizophrenia according to ICD-10 (WHO, 1992) with a history of illness of past two years were selected. Twenty subjects were selected from IPD and 20 subjects from OPD of Post-Graduate Institute of Behavioral and Medical Sciences, Raipur using purposive sampling method. For the caregivers, both male, female with no prior history of any kind of physical or mental illness was included in the study.

\section{Tools}

Socio-Demographic and Clinical Data Sheet: Self prepared socio-demographic and clinical data sheet was used to collect the information regarding patient's and their caregiver's age, sex, religion, family type, family history, income and occupation. Additional information was also gathered regarding type of admission, diagnosis of patient, persons sharing responsibility of patient, earning members in family, knowledge about patient's illness and attitude towards illness.

Brief Psychiatric Rating Scale (BPRS): The Brief Psychiatric Rating Scale is a 24-item measure that assesses the severity of mental illness (Ventura et al., 1993). The 24 items are rated on a 7-piont scale ranging from 'not present' to 'extreme severe'. A total score ranging from 24 to 168 can be calculated with higher scores reflecting higher severity. Reliability coefficients of 0.56 to 0.87 have been reported by the authors.

\section{The World Health Organization Quality of Life (WHOQOL-BREF):}

It is 26-item measure to assess the quality of life (WHO, 2004). Items are rated on 5-point scale and measures the quality of life in four domains namely physical health, psychological, social relationships and environment along with the overall quality of life. The alpha score of all domain ranges from 0.59 to 0.87 , Cronbach alpha of the all domains are 0.87 , the factor loadings of the item ranges from 0.52 to 0.84 .

\section{PROCEDURE}

Caregivers of 40 diagnosed schizophrenia patients (as per ICD 10) were selected through purposive sampling technique, 20 each from inpatient and outpatient of Post-Graduate Institute of Behavioral and Medical Sciences, Raipur. Both the groups were matched with respect to age and sex. After having informed consent for the study from the care givers, socio-demographic details of both patients and caregivers were collected. Brief Psychiatric Rating Scale was administered on the patients to find out the severity of the symptoms. Finally, quality of life of care givers of the patients was assessed by using World Health Organization Quality of Life- BREF.

\section{STATISTICAL ANALYSIS}

Scores thus obtained were analyzed with Statistical Package for Social Sciences (SPSS). Descriptive statistics (percentages and mean), Chi-Square \& ttest were used to see the significant differences, if any.

\section{RESULTS AND DISCUSSION}

Table 1 shows the socio demographic profile of caregivers of outpatient and inpatient schizophrenia patients. It is clear from the table that no significant difference has been found among the caregivers of outpatient and inpatient schizophrenia patients. It was observed that most of the caregivers of outpatients were males, literates, by occupation farmers, married, were spouse in relation to the patients who mostly spent more than 12 hours, had a family income of less than 5,000, had knowledge about mental illness and had a positive attitude towards patient's mental illness. It is also reflected in the table that majority of the the caregivers of inpatients were females, literates, housewife by occupation, married, illiterates, were farmers by occupation, married, were parents in relation to the patients who mostly spent more than 12 hours, had a family income of less than Rs. 5, 000, had knowledge about mental illness and had a positive attitude towards patient's mental illness. 
Table 1: Sample Characteristics

\begin{tabular}{|l|l|l|l|l|}
\hline \multicolumn{2}{|c|}{ Variables } & M & (SD) & t-value \\
\hline Age & OPD & 43.20 & $(13.87)$ & \multirow{2}{*}{0.66} \\
\hline & IPD & 46.30 & $(15.72)$ & \\
\hline
\end{tabular}

\begin{tabular}{|c|c|c|c|c|c|c|}
\hline \multicolumn{2}{|c|}{ Variables } & \multicolumn{2}{|c|}{ OPD } & \multicolumn{2}{|r|}{ IPD } & \multirow{2}{*}{$\begin{array}{l}\mathrm{X}^{2} \\
\text { value }\end{array}$} \\
\hline & & $\mathbf{N}$ & $\%$ & $\mathbf{N}$ & $\%$ & \\
\hline \multirow[t]{2}{*}{ Sex } & Male & 13 & $(65.0 \%)$ & 7 & $(35.0 \%)$ & \multirow[t]{2}{*}{3.60} \\
\hline & Female & 7 & \begin{tabular}{|l|}
$(35.0 \%)$ \\
\end{tabular} & 13 & $(65.0 \%)$ & \\
\hline \multirow[t]{2}{*}{ Education } & Literate & 12 & \begin{tabular}{|l|}
$(16.0 \%)$ \\
\end{tabular} & 7 & $(35.0 \%)$ & \multirow[t]{2}{*}{0.10} \\
\hline & Illiterate & 8 & $(40.0 \%)$ & 13 & $(65.0 \%)$ & \\
\hline \multirow[t]{4}{*}{ Occupation } & House wife & 6 & $(30.0 \%)$ & 9 & $(45.0 \%)$ & \multirow[t]{4}{*}{5.82} \\
\hline & \begin{tabular}{|l|} 
Student \\
\end{tabular} & 1 & $(5.0 \%)$ & 1 & $(5.0 \%)$ & \\
\hline & Service & 5 & $(25.0 \%)$ & 0 & $(0.0 \%)$ & \\
\hline & Farmer/labour & 8 & $(40.0 \%)$ & 10 & $(50.0 \%)$ & \\
\hline \multirow[t]{3}{*}{ Marital Status } & Married & 17 & $(85.0 \%)$ & 14 & $(70.0 \%)$ & \multirow[t]{3}{*}{4.49} \\
\hline & Unmarried & 3 & $(15.0 \%)$ & 2 & $(10.0 \%)$ & \\
\hline & $\begin{array}{l}\text { Widow/Divorced } \\
\text { /Separated }\end{array}$ & 0 & $(0.0 \%)$ & 4 & $(20.0 \%)$ & \\
\hline \multirow{4}{*}{ Relation with the patient } & Spouse & 9 & $(45.0 \%)$ & 6 & $(30.0 \%)$ & \multirow[t]{4}{*}{3.92} \\
\hline & Parents & 7 & $(35.0 \%)$ & 12 & $(60.0 \%)$ & \\
\hline & Sibling & 2 & $(10.0 \%)$ & 2 & $(10.0 \%)$ & \\
\hline & Other & 2 & $(10.0 \%)$ & 0 & $(0.0 \%)$ & \\
\hline \multirow{2}{*}{$\begin{array}{l}\text { Hours spend daily } \\
\text { with the patient }\end{array}$} & 12 hours & 8 & $(40.0 \%)$ & 8 & $(40.0 \%)$ & \multirow[t]{2}{*}{0.00} \\
\hline & $>12$ hours & 12 & $(60.0 \%)$ & 12 & $(60.0 \%)$ & \\
\hline \multirow[t]{3}{*}{ Family income } & 5,000 & 9 & $(45.0 \%)$ & 13 & $(65.0 \%)$ & \multirow[t]{3}{*}{1.84} \\
\hline & $5,000-10,000$ & 5 & $(25.0 \%)$ & 4 & $(20.0 \%)$ & \\
\hline & $>10,000$ & 6 & $(30.0 \%)$ & 3 & $(15 \%)$ & \\
\hline \multirow{3}{*}{$\begin{array}{l}\text { Knowledge about } \\
\text { patient's illness }\end{array}$} & Mental illness & 16 & $(80.0 \%)$ & 17 & $(85.0 \%)$ & \multirow[t]{3}{*}{4.03} \\
\hline & \begin{tabular}{|l}
$\begin{array}{l}\text { Effect of } \\
\text { supernatural }\end{array}$ \\
\end{tabular} & 1 & $(1.0 \%)$ & 3 & $(15.0 \%)$ & \\
\hline & Any other & 3 & $(15.0 \%)$ & 0 & $(0.0 \%)$ & \\
\hline \multirow{2}{*}{$\begin{array}{l}\text { Attitude of family } \\
\text { members towards illness }\end{array}$} & Positive & 20 & $(100.0 \%)$ & 18 & $(90.0 \%)$ & \multirow[t]{2}{*}{2.11} \\
\hline & Negative & 0 & $(0.0 \%)$ & 2 & $(10.0 \%)$ & \\
\hline
\end{tabular}

Table 2: Quality of Life among Caregivers of outpatient and inpatient schizophrenia patients

\begin{tabular}{|l|ll|ll|l|}
\hline \multirow{2}{*}{ Variables Subjects } & \multicolumn{4}{|c|}{ Schizophrenia Patients } & \multirow{2}{*}{ t-value } \\
\cline { 2 - 5 } & OPD Patients & \multicolumn{2}{|c|}{ IPD Patients } & \multirow{2}{*}{} \\
\cline { 2 - 5 } & $\mathbf{M}$ & (SD) & M & (SD) & \\
\hline Physical Health & 14.20 & $(2.41)$ & 13.85 & $(2.03)$ & 0.49 \\
\hline Psychological Well Being & 13.75 & $(2.14)$ & 1.90 & $(2.59)$ & 1.13 \\
\hline Social Relationships & 13.70 & $(2.29)$ & 11.45 & $(4.04)$ & $\mathbf{2 . 1 6 * *}$ \\
\hline Environmental Conditions & 13.15 & $(1.32)$ & 12.85 & $(2.15)$ & 0.42 \\
\hline
\end{tabular}

*p 0.05 level (2-tailed)

Table 2 reflects quality of life among the caregivers of outpatient and inpatient schizophrenia patients. It is quite obvious from the table that caregivers of outpatient schizophrenia patients were having less health related problems in comparison to the caregivers of inpatient schizophrenia. However, difference was not found significant statistically (OPD: $\mathrm{M}= \pm 13.76, \mathrm{t}=0.49$; IPD: $\mathrm{M}= \pm 13.85, \mathrm{t}=0.49 ; \mathrm{p} 0.05)$. It is also noticed that psychological problems were less in the caregivers of outpatient schizophrenic patients than inpatient schizophrenic patients but the difference was not significant statistically (OPD: $\mathrm{M}= \pm 13.75, \mathrm{t}=1.13$; IPD: $\mathrm{M}= \pm 1.90, \mathrm{t}=1.13 ; \mathrm{p} 0.05)$. Caregivers of outpatient schizophrenic patients were more satisfied in their environmental conditions than the caregivers of inpatient schizophrenia patients but the difference was not significant statistically (OPD: $\mathrm{M}= \pm 13.15, \mathrm{t}=0.42$; IPD: $\mathrm{M}= \pm 12.85, \mathrm{t}=0.42 ; \mathrm{p} 0.05$ ).

It has been noticed that in the area of social relationships, significant difference is there among the caregivers of outpatient and inpatient schizophrenia patients and the difference is significant statistically (OPD: $\mathrm{M}= \pm 13.70$, $\mathrm{t}=$ 2.16; IPD: $M= \pm 11.45, t=2.16 ; p$ 0.05). Quality of life of caregivers of inpatient schizophrenic patients has more problems in social functioning like impaired interpersonal relationships, poor social support from other relatives, problems in sexual activity have also been found in some cases.

Studies have shown that admitted schizophrenic patients' caregivers had lower level of satisfaction in social relations domain (Galuppi., et al, 2010). Solanki (2010) has concluded negative effect of illness on social functioning of the family members' of schizophrenic patients in a study in Jaipur, India. Another study on admitted schizophrenic patients by Saffar \& Yaseen (2009) reported lower quality of life in the domain of social relationships. The difference in quality of life of care givers of outpatients and inpatients may be because of difference in severity of symptoms as inpatients has relatively more severe symptoms than outpatients. Another reason may be that in India, families and social relationships are given very high importance and play an integral part in everybody's lives. If in any family, one of the members suffers from mental illness, the other family members play a very important role in providing support to the person. Because of that, caregivers often don't get time for other issues. In case when the patient is staying at home, at times the caregivers can discharge their psychological and occupational responsibilities, keeping some other family member to watch and care for the patient. But when the patient is admitted in a hospital, the family members has to be more alert regarding the functioning of the patient in hospital, to visit there, in case of emergency. As a result social relationships gets affected due to the presence of disagreements, conflicts among the other members of the family causing lack of social support 
and more damage in caregivers' social life. In addition, some close relatives might go away avoiding the responsibility to take care of such patients. Jungbauer et al., (2002) reported that in a study majority of the caregivers in India felt that the patients' illness prevents them from having a satisfying relationship with the rest of the family members and other people.

Table 3: Correlation among the BPRS and WHOQOL-BREF

\begin{tabular}{|c|l|l|l|l|}
\hline Variables & $\begin{array}{l}\text { Physical } \\
\text { Health }\end{array}$ & $\begin{array}{l}\text { Psychological } \\
\text { Well Being }\end{array}$ & $\begin{array}{l}\text { Social } \\
\text { Relationships }\end{array}$ & $\begin{array}{l}\text { Environmental } \\
\text { Conditions }\end{array}$ \\
\hline BPRS & $\mathbf{- 0 . 3 2 5}^{*}$ & -0.179 & 0.132 & -0.127 \\
\hline
\end{tabular}

*p 0.05 level

Table 3 shows the correlation between BPRS and WHOQOL-BREF scores in the caregivers of outpatient and inpatient schizophrenia patients. It is reflected in the table that there is a significant negative correlation in the area of physical health and BPRS scores $(\mathrm{r}=-0.325$; $\mathrm{p}$ 0.05). No significant correlation was found between BPRS and WHOQOL-BREF scores in other areas among the caregivers of outpatient and inpatient schizophrenia patients. It is also clear from the table that the more severe the illness was, the more negative effect it had on the physical health of the caregivers. Previous studies have shown that physical, emotional, economic distress affect negatively caregiver's physical health as a result of a number of unfulfilled needs such as restoration of patient functioning in family and social roles, economic burden, lack of spare time. Decreased physical health may be associated with caregivers' burden, lack of social support, course of the disease and family relationships problems. (Caqueo-Urizar et al., 2009). If the caregiver is working, then working life is also significantly affected. At time, they had to leave their jobs, modify their working hours or change to another job. Moreover, in some cases, stress seemed to be associated with a triple shift: job, household duties, and care for a patient. As a result of which stress problems, anxiety and depression were commonly observed in caregivers. Lower level of satisfaction in physical health domain was reported by Bobes et al (1996) on the caregivers of a sample of 78 schizophrenic patients.

\section{CONCLUSION}

Quality of life of caregivers of inpatient schizophrenic patients has more problems in social functioning like impaired interpersonal relationships, poor social support from other relatives, problems in sexual activity have also been found in some cases. Caregivers face a lot of problem in their physical health also like lack of energy, fatigability, pain, discomfort, disturbed sleep, inability to relax and impaired work performance when the symptoms of the schizophrenic patient increases. However, there are a few limitations of this study like the sample size was small, other variables like burden, social support was not included, gender differences with respect to caregivers was not assessed.

\section{REFERENCES}

1. Alejandra, C-U., José, G-M., Claudia, M-C. (2009) Quality of life in caregivers of patients with schizophrenia: A literature review. Health Quality Life Outcomes, 7: 84.

2. Bobes, J., Gonzalez, M. P., Bousono, M (1996) Quality of life instruments in schizophrenia: A comparative study.Europian Psychiatry, 11 (suppl 4): $228 \mathrm{~s}-228 \mathrm{~s}(1)$.

3. Dwyer, J., Lee, G., Jankowski, T. (1994) Reciprocity, Elder Satisfaction and Caregiver Stress \& Burden: The Exchange of Aid in the Family Care-giving Relationship. Journal of Marriage \& Family, 56, 35-43.

4. Dyck, D., Short, R., Vitaliano, P. (1999) Predictors of Burden and Infectious Illness in Schizophrenia Caregivers. Psychosomatic Medicine, 61, 411-419.

5. Emerson, E. (1985) Evaluating the impact of deinstitutionalization on the lives of mentally retarded people. American Journal of Mental Deficiency, 90(3), 277-288.

6. Fadden, G., Bebbington, P., Kuipers, L. (1987) The burden of care: The impact of functional psychiatric illness on the patient's family. British Journal of Psychiatry, 150, 285-292.

7. Farrell, B. (1995) The impact of pain on quality of life. A decade of research. The Nursing Clinics of North America, 30(4), 609-624.

8. Galuppi, A., Turola, M. C., Nanni, M. G., Mazzoni,P. (2010) Schizophrenia and quality of life: how important are symptoms and functioning?. International Journal of Mental Health Systems , 4, 31-39.

9. Jungbauer, J., \& Angermeyer, M. (2002) Living with a Schizophrenic Patient: A Comparative Study of Burden as It Affects Parents and Spouses. Psychiatry, 65, 110-123. 
10. Oort, F. (2005) Using structural equation modelling to detect response shifts and true change. Quality of Life Research, 14(3), 587-598.

11. Oort, F., Visser, M., \& Sprangers, M. (2005) An application of structural equation modelling to detect response shifts and true change in quality of life data from cancer patients undergoing invasive surgery. Quality of Life Research, 14(3), 599-609.

12. Solanki, R. K. (2010) Disability \& Quality of Life in Schizophrenia and Obsessive Compulsive Disorder: A Cross-Sectional Comparative Study. East Asian Archives of Psychiatry, 20 (1), 7-13.

13. Saffar, N. M. AL \& Yaseen, Y. A. (2009) Quality of life in Schizophrenic Patients in Duhok City. Tikrit Medical Journal, 15(2), 79-86.

14. WHOQOL Group (1994) Development of the WHOQOL: Rationale and current status. International Journal of Mental Health, 23, 24-56.

15. Yesavage, J. A. (1983) Inpatient violence and the schizophrenic patient. A study of Brief Psychiatric Rating Scale scores and inpatient behaviour. Acta Psychiatrica Scandinavica, 67(5), 353-357.
Authors:

1. Anwesha Mondal, Ph.D. Scholar, Dept. of Clinical Psychology, RINPAS, Kanke, Ranchi

2. Mir Shahid Ali, Consultant Clinical Psychologist Tulasi Psychiatric and Rehabilitation Pvt Ltd, New Delhi

3. J Mahto, Professor and Head of Department of Clinical Psychology PGIBAMS, Raipur, Chhattisgarh

4. Jai Prakash, Additional Professor of Clinical Psychology, RINPAS, Kanke, Ranchi

\section{Corresponding Author}

Dr. Jai Prakash

Additional Professor of Clinical Psychology, RINPAS

Kanke, Ranchi

Tel : +91-9934582290

E-mail: drjaiprakashrinpas@rediffmail.com 